\title{
PERAN BIDAN DALAM PELAKSANAAN PERMENKES NOMOR 631/MENKES/ PER/III/2011 \\ SEBAGAIMANA TELAH DIUBAH DENGAN PERMENKES NOMOR 2562/MENKES/PER/XII/2011 TENTANG PETUNJUK TEKNIS JAMINAN PERSALINAN
}

(Studi Kasus Pelayanan Kebidanan Di RSUD dr. H. Soewondo Kendal)

\author{
Sariyati, Endang Wahyati Y. dan C. Tjahjono Kuntjoro \\ sariyati_73@yahoo.com \\ Magister Hukum Kesehatan \\ Universitas Katolik Soegijapranata Semarang
}

\begin{abstract}
The role of midwives in service delivery assurance in $\mathrm{dr}$. $\mathrm{H}$. Soewondo Kendal based on Permenkes No. 2562/MENKES /PER/XII/2011 on Technical Guidelines for Labor Warranty. The aim is to implement the appropriate authority midwifery services, with the ultimate goal of reducing the MMR (Maternal Mortality Rate) and IMR (Infant Mortality Rate). If viewed from Permenkes 1464/Menkes /Per/X/2010 number of licenses and the implementation of midwifery practice, it is not really appropriate authority for the role of the midwife in the hospital to service delivery is a delivery service assurance of advanced midwives in hospitals. The scope of service includes pregnant women, maternity (risti), childbirth, newborns, family planning and treatment of complications in obstetrics. So based on the authority role of the midwife in the hospital should not be for the scope of services for maternity delivery guarantee (risti) and treatment of complications in obstetrics.
\end{abstract}

Keywords : Role of Midwives, Maternity Insurance, Midwifery Services in Hospitals 


\section{PENDAHULUAN}

\section{Latar Belakang}

Salah satu masalah kesehatan di indonesia adalah tingginya Angka Kematian Ibu (AKI) dan Angka Kematian Bayi (AKB) hal ini perlu mendapat perhatian dengan melaksanakan progam perbaikan dan peningkatan kesehatan ibu, upaya perbaikan ini terutama oleh departemen kesehatan melalui progam kesehatan ibu dan anak. ${ }^{1}$ Persalinan adalah proses membuka dan menipisnya serviks, dan janin turun kedalam jalan lahir. Kelahiran bayi merupakan peristiwa sosial yang ibu dan keluarga menantikannya sembilan bulan. Ketika persalinan dimulai, peranan ibu adalah melahirkan bayinya, sedangkan tenaga kesehatan berperan memantau persalinan, mendeteksi dini adanya komplikasi, disamping itu bersama keluarga memberikan bantuan dan dukungan pada ibu bersalin. ${ }^{2}$ Bidan memiliki peran untuk memberikan pelayanan kebidanan (kesehatan reproduksi) kepada perempuan, remaja putri, calon pengantin, ibu hamil, bersalin, nifas, masa interval, klimakterium, dan menopouse, bayi baru lahir, anak balita, dan pra sekolah, selain itu bidan juga punya peran untuk merujuk ke pelayanan/fasilitas pelayanan kesehatan lain secara horisontal maupun vertikal ke profesi lain, serta peran bidan sebagai pengembangan dan peningkatan kemampuan dukun bayi, kader, dan tenaga kesehatan sebagai pendidik, penyuluh bagi klien ${ }^{3}$.

Cara meningkatkan akses terhadap pelayanan persalinan yang dilakukan oleh bidan atau dokter dalam rangka menurunkan AKI dan AKB untuk angka kematian ibu ditargetkan turun menjadi 120/100.000 kelahiran hidup, maka pemerintah membuat Permenkes Nomor 515/MENKES/SK/III/2011 tentang penerimaan dana penyelenggaraan Jaminan Kesehatan Masyarakat dan Jaminan Persalinan di pelayanan dasar tiap Kabupaten/Kota Tahun Anggaran 2011. Adapun dalam memberikan jaminan pembiayaan untuk pelayanan persalinan (Jampersal), maka pemerintah menetapkan program ini dengan Peraturan Menteri Kesehatan RI Nomor Permenkes Nomor 631/Menkes/ Per/III/2011 Sebagaimana Telah Diubah Dengan 2562/ Menkes/ Per/XII/2011 tentang Petunjuk Teknis Jaminan Persalinan.

\section{Perumusan Masalah}

Berdasarkan uraian dari latar belakang diatas dapat dirumuskan masalah yaitu :

a. Bagaimana pengaturan peran bidan dalam pelaksanaan Jaminan Persalinan berdasarkan kewenangan bidan?

b. Bagaimana pelaksanaan peran Bidan berdasarkan Permenkes Nomor 631/Menkes/ Per/III/2011 sebagaimana telah diubah dengan Permenkes Nomor 2562/Menkes/Per/XII/2011 tentang Petunjuk Teknis Jaminan Persalinan di RSUD dr. H. Soewondo Kendal?

c. Bagaimana faktor-faktor yang mempengaruhi pelaksanaan Permenkes Nomor 631/Menkes/ Per/III/2011 sebagaimana telah diubah dengan Permenkes Nomor 2562/Menkes/Per/XII/2011 tentang Petunjuk Teknis Jaminan Persalinan di RSUD dr. H. Soewondo Kendal?

1 Depkes RI, 2005, Rencana Strategi Depkes RI, Jakarta.

2 Sarwono Prawitoharjo, 2002, Buku Acuan Nasional Pelayanan Kesehatan Maternal dan Neonatal, Cetakan Ketiga, JNPKKR : POGI, Hal 100.

3 Febrina, 12 Februari 2010, Standar Praktik Kebidanan, Jakarta. 


\section{Tujuan Penelitian}

a. Untuk mendapatkan gambaran tentang pengaturan peran bidan dalam pelaksanaan Jaminan Persalinan berdasarkan kewenangan bidan

b. Untuk mendapatkan gambaran tentang pelaksanaan peran bidan berdasarkan Permenkes Nomor 631/Menkes/ Per/III/2011 sebagaimana telah diubah dengan Permenkes Nomor 2562/Menkes/Per/XII/2011 tentang Petunjuk Teknis Jaminan Persalinan di RSUD dr. H. Soewondo Kendal.

c. Untuk mendapatkan gambaran tentang faktor-faktor yang mempengaruhi pelaksanaan Permenkes Nomor 631/Menkes/ Per/lii/2011 sebagaimana telah diubah dengan Permenkes Nomor 2562/Menkes/Per/XII/2011 tentang Petunjuk Teknis Jaminan Persalinan di RSUD dr. H. Soewondo Kendal.

\section{Manfaat Penelitian}

a. Praktis

1) Bagi bidan

Sebagai masukan untuk menambah pengetahuan dan motivasi bidan dalam pelaksanaan Permenkes Nomor 631/Menkes/Per/III/2011 sebagaimana telah diubah dengan Permenkes Nomor 2562/Menkes/Per/XII/2011 tentang Petunjuk Teknis Jaminan Persalinan.

2) Bagi Rumah Sakit

Sebagai bahan pertimbangan untuk menetapkan langkah-langkah selanjutnya dan dapat dijadikan sebagai dasar pengambilan keputusan.

3) Bagi Pemerintah

Sebagai bahan bagi pemerintah, khususnya Pemerintah kabupaten Kendal dalam membuat kebijakan tentang Pelaksanaan Jampersal.

b. Akademis

Hasil penelitian ini dapat menambah khasanah dalam perkembangan ilmu pengetahuan dan dapat digunakan untuk penelitian berikutnya khususnya di bidang Hukum Kesehatan yang berkaitan dengan Jaminan Persalinan dalam pelaksanaan tugas di pelayanan kesehatan.

\section{Metode Penelitian}

Penelitian ini dimaksudkan untuk memperoleh informasi tentang pelaksanaan pelayanan jaminan persalinan yang dilakukan oleh Rumah Sakit, untuk keperluan penulisan tesis yang berjudul "Peran Bidan Dalam Pelaksanaan Permenkes Nomor 631/Menkes/ Per/III/2011 sebagaimana telah diubah dengan Permenkes Nomor 2562/Menkes/Per/XII/2011 Tentang Petunjuk Teknis Jaminan Persalinan".

Data yang dikumpulkan meliputi hal-hal yang berkaitan dengan pelaksanaan jaminan persalinan yang dilakukan oleh bidan di Rumah Sakit.

\section{a. Metode Pendekatan}

Metode yang digunakan dalam penelitian ini adalah penelitian yuridis sosiologis secara kualitatif, yaitu aspek yuridis yang diteliti adalah peraturan tentang pelayanan jaminan persalinan. Aspek sosiologis yang diteliti adalah pelaksanaan jaminan persalinan oleh bidan di Rumah Sakit dr. H. Soewondo Kendal sebagai data primer penelitian yang diperoleh menggunakan metode wawancara secara bebas terpimpin dan mendalam serta mengisi kuesioner. 


\section{b. Spesifikasi Penelitian}

Penelitian ini bersifat deskriptif, yang bertujuan untuk mendiskripkan secara sistematis, faktual dan akurat terhadap suatu populasi tertentu, mengenai sifat-sifat, karakteristik-karakteristik atau faktor-faktor tertentu ${ }^{4}$ yaitu tentang peran bidan dalam pelaksanan pelayanan kebidanan di RSUD dr. H Soewondo Kendal.

\section{c. Jenis Data}

1) Data primer yaitu data yang diperoleh langsung dari responden melalui penelitian lapangan dalam studi kasus. Dengan cara wawancara, observasi, kuesioner dengan responden yaitu :

a) Direktur RSUD dr. H. Soewondo Kendal berjumlah = 1 orang

b) Kepala Bangsal Ruang Bersalin dan Ruang Bayi RSUD dr. H. Soewondo Kendal berjumlah $=2$ orang

c) Bidan yang bertugas di Ruang Bersalin, Ruang Bayi dan IGD RSUD dr. H. Soewondo Kendal berjumlah 26 orang

d) Pasien yang menerima Jaminan Persalinan di RSUD dr. H. Soewondo Kendal $=10$ orang

2) Data sekunder yaitu data yang diperoleh dari kepustakaan guna untuk mendapatkan landasan teoritis berupa pendapat- pendapat atau tulisan para ahli atau pihak yang berwenang dan juga untuk memperoleh informasi baik dalam bentuk formal maupun naskah resmi yang ada.

\section{d. Variabel dan Definisi Operasional}

1) Dalam melakukan tinjauan teoritis, peneliti perlu mengidentifikasikan variabelvariabel yang relevan dengan permasalahan pokok penelitiannya.

Adapun unsur-unsur dalam penelitian ini adalah:

a) Ketentuan tentang peran bidan dalam pelaksanaan Permenkes Nomor 631/Menkes/ Per/III/2011 sebagaimana telah diubah dengan Permenkes 2562/Menkes/Per/XII/2011 tentang Petunjuk Teknis Jaminan persalinan.

b) Pelaksanaan peran bidan di RSUD dr. H. Soewondo Kendal tentang Permenkes Nomor 631/Menkes/ Per/III/2011 sebagaimana telah diubah dengan Permenkes 2562/Menkes/Per/XII/2011 dalam pelayanan Jaminan Persalinan

c) Faktor-faktor yang mempengaruhi pelaksanaan Permenkes Nomor 631/Menkes/ Per/III/2011 sebagaimana telah diubah dengan Permenkes 2562/Menkes/Per/XII/2011 tentang Petunjuk Teknis Jaminan Persalinan.

2) Definisi Operasional

Untuk menguji hipotesis, peneliti harus memastikan variabel-variabel mana saja yang akan dilibatkan dalam penelitiannya.

4 Ronny Hanitijo Soemitro, 1988, Metode Penelitian Hukum dan Jumimetri, Jakarta. Balai Aksara Yudistira. 
Untuk menentukan instrumen maka variabel-variabel tersebut. Harus didefinisikan dan diklasifikasikan sebagai berikut :

a) Pelayanan kesehatan adalah tempat atau sarana yang harus digunakan untuk menyelenggarakan upaya kesehatan.

b) Peran merupakan seperangkat tingkah laku yang diharapkan oleh suatu kelompok tertentu (dapat berbentuk individu, kelompok, keluarga, dan masyarakat) sesuai dengan kedudukannya dalam suatu sistem kelompok yang dimaksud dalam peran adalah kelompok masyarakat sebagai pengguna jasa kebidanan dan kelompok peran bidan merupakan bentuk perilaku profesional yang diharapkan oleh masyarakat dan organisasi profesi.

c) Bidan adalah seorang tenaga kesehatan yang mempunyai tugas penting dalam bimbingan dan penyuluhan pada ibu hamil, persalinan, nifas, dan menolong persalinan dengan tanggung jawabnya sendiri serta memberikan asuhan kepada bayi baru lahir (prenatal care).

d) Permenkes Nomor 631/Menkes/ Per/III/2011 sebagaimana telah diubah dengan Permenkes Nomor 2562/Menkes/ Per/XII/2011 tentang Petunjuk Teknis Jaminan Persalinan.

\section{e. Metode Pengumpulan Data}

Untuk memperoleh data yang akurat dalam penelitian ini maka cara mengumpulkan data primer dalam studi (penelitian) lapangan dilakukan penelitian langsung pada obyeknya, dengan cara ${ }^{5}$ :

1) Studi Kepustakaan, yaitu data yang diteliti dalam suatu penelitian dapat berwujud data yang diperoleh melalui bahan-bahan kepustakaan dan secara langsung dari masyarakat.

2) Pengamatan (observasi), pengamatan langsung pada responden yaitu semua bidan yang ada di RSUD dr H. Soewondo kendal.

3) Wawancara (interview), cara untuk memperoleh informasi dengan bertanya langsung pada responden yaitu direktur, kepala bangsal, bidan praktik dan pasien.

4) Daftar pertanyaan (kuesioner), alat untuk mendapatkan data dari populasi yang luas atau yang terdiri dari beraneka macam golongan.

Berkaitan dengan penelitian tersebut, untuk memperoleh data yang akurat perlu subyek penelitian dan alat pengumpul data yang tepat antara lain :

1) Subyek Penelitian

Subyek penelitian ini sebagai sumber informasi dalam penelitian. Pengambilan dilakukan dengan cara teknik non probality sampling secara purposive sampling yaitu teknik penentuan sampel dengan pertimbangan tertentu yang dibuat oleh peneliti sendiri, berdasarkan ciri atau sifat-sifat populasi yang sudah diketahui sebelumnya. ${ }^{6}$ Adapun ciri dan sifat yang dimaksud adalah:

a) Subyek merupakan Direktur RSUD dr. H. Soewondo Kendal yaitu penanggung jawab dalam Rumah Sakit.

5 Ronny Hanitijo Soemitro, 1988, Metode Penelitian Hukum dan Jurimetri, Jakarta, Ghalia Indonesia. Hal 51.

6 Soekidjo Notoadmodjo, op.cit., hal 124-125. 
b) Subyek merupakan Kepala Bangsal Ruang Bersalin dan Ruang Bayi RSUD dr. H. Soewondo Kendal yaitu bertugas untuk mengatur pelaksanaan pelayanan di bagian Ruang Bersalin dan Ruang Bayi.

c) Bidan yang bertugas di Ruang Bersalin, Ruang Bayi dan IGD RSUD dr. H. Soewondo Kendal yaitu bidan sebagai pelaksana dan pemberi pelayanan bagian kebidanan.

d) Pasien yang menerima Jaminan Persalinan di RSUD dr. H. Soewondo Kendal yaitu penerima pelayanan jaminan persalinan di Rumah Sakit.

2) Alat (instrument) Pengumpul Data

Mengingat akan perbedaan jenis-jenis data yang diperlukan dalam penelitian ini, maka alat (instrument) yang dipergunakan untuk mengumpulkan data primer dibedakan dari alat (instrument) untuk pengumpul data sekunder.

Untuk mengumpulkan data primer dalam studi (penelitian) lapangan, digunakan alat pengumpul data berupa :

1) Observasi langsung yaitu melakukan pengamatan langsung pada responden yaitu semua bidan yang ada di RSUD dr H. Soewondo kendal .

2) Wawancara yaitu dilakukan dengan memakai pedoman wawancara. Mula-mula kepada subyek penelitian diajukan pertanyaan yang sudah terstruktur, selanjutnya atas beberapa butir pertanyaan tersebut diperdalam untuk mendapatkan keterangan lebih lanjut, sehingga dapat diperoleh jawaban yang lengkap dan mendalam. ${ }^{7}$

3) Kuesioner alat yang dipergunakan untuk mendapat data dari populasi, untuk memilih sampel yang representatif diperlukan tehnik sampling. ${ }^{8}$ Adapun penelitian sampel ini merupakan cara penelitian yang dilakukan hanya terhadap sampel-sampel dari populasi saja. Adapun alasan-alasan cara ini dipilih karena : penelitian sampel dapat dilakukan lebih cepat dan lebih murah, dapat menghasilkan informasi yang lebih komprehensif, sampel akurat penghematan waktu dan biaya.

\section{f. Metode Analisa Data}

Analisa data adalah proses mencari dan menyusun secara sistematis suatu data untuk selanjutnya dianalisa secara kualitatif, untuk mencapai kejelasan masalah yang akan dibahas yaitu peran bidan dalam pelaksanan Permenkes Nomor 631/Menkes/ Per/III/2011 sebagaimana telah diubah dengan Permenkes Nomor 2562/Menkes/Per/XII/2011 tentang Petunjuk Teknis Jaminan Persalinan. ${ }^{9}$

7 Bambang Sunggono, 2010, Metodologi Penelitian Hukum, Jakarta : Rajawali Pers, hal.40.

8 Ronny Hanitijo Soemitro, 1988, Metode Penelitian Hukum dan Jurimetri, Jakarta, Ghalia Indonesia. Hal 47.

9 Beni Ahmad soebani, Metode Penelitian Hukum, 2009, Bandung,Pustaka Setia. Hal 66. 


\section{HASIL PENELITIAN DAN PEMBAHASAN}

\section{Gambaran Umum RSUD dr. H. Soewondo Kendal}

\section{a. Profil RSUD dr. H. Soewondo Kendal}

Visi dari RSUD dr. H.Soewondo Kendal yaitu menjadi rumah sakit yang mampu memberikan pelayanan prima yang didukung oleh SDM yang profesional dan sejahtera, sarana dan prasarana memadai serta manajemen yang dapat dipertanggungjawabkan. Misi dari RSUD dr. H. Soewondo Kendal yaitu Meningkatkan profesional SDM, Meningkatkan kesejahteraan SDM, Mengembangkan sarana dan prasarana, Mengembangkan manajemen pelayanan rumah sakit, Memberikan pelayanan prima yang terjangkau dan didukung jaringan pelayanan kesehatan.

\section{b. Struktur Organisasi RSUD dr. H. Soewondo Kendal}

Dengan susunan organisasi RSUD dr. H. Soewondo Kendal maka memiliki tugas dan fungsi masing-masing antara lain Direktur, Wakil Direktur Administrasi Umum dan Keuangan, Wakil Direktur Pelayanan, Komite Medik, Komite Keperawatan, Satuan Pemeriksaan Internal, Instalansi, Dewan Pengawas, Kelompok Jabatan Fungsional

\section{Pengaturan Peran Bidan Dalam Pelaksanaan Jaminan Persalinan Berdasarkan Kewenangan Bidan}

Dalam perannya bidan melaksanakan jaminan persalinan berdasarkan kewenangannya diatur dalam beberapa dasar hukum antara lain :

a. Dasar Hukum

Undang-Undang Sistem Jaminan Sosial Nasional Nomor 40 Tahun 2004, Undang-Undang Kesehatan Nomor 36 Tahun 2009, Undang-Undang Rumah Sakit Nomor 44 Tahun 2009, Permenkes Nomor 1464/Menkes/Per/X/2010

b. Bentuk Pengaturan

Pada Permenkes Nomor 1464/Menkes/Per/X/2010 tentang ljin dan Penyelenggaraan Praktik Bidan bahwa kewenangan bidan dalam pelayanan kebidanan meliputi hamil, bersalin, nifas dan bayi baru lahir sedangkan pada Permenkes Nomor 631/Menkes/ Per/III/2011 sebagaimana telah diubah dengan Permenkes Nomor 2562/Menkes/ Per/XII/2011 tentang Petunjuk Teknis Jaminan Persalinan bahwa pelayanan jaminan persalinan dilaksanakan secara berjenjang pada pelayanan tingkat lanjut dan tingkat dasar. Pelayanan tingkat lanjut meliputi pemeriksaan kehamilan dengan risti, persalinan risti, komplikasi dan KB pasca persalinan dan pada pelayanan tingkat dasar meliputi pemeriksaan kehamilan, pertolongan persalinan, pelayanan nifas dan pelayanan KB pasca salin, serta pelayanan kesehatan bayi baru lahir, termasuk pelayanan persiapan rujukan. Peran bidan berdasarkan penelitian di RSUD dr. H. Soewondo Kendal belum ditetapkan secara tertulis, dan tidak sesuai dengan kewenangan bidan yang diatur dalam Permenkes Nomor 1464/Menkes/Per/X/2010 tentang ljin dan Penyelenggaraan Praktik Bidan.

c. Tujuan Pengaturan

1) Melaksanakan program pemerintah yakni program jaminan persalinan yang tujuan akhirnya adalah untuk menurunkan angka kematian ibu dan angka kematian bayi atau balita;

2) Melaksanakan pelayanan jaminan persalinan sesuai dengan petunjuk teknis 


\section{Pelaksanaan Peran Bidan Berdasarkan Permenkes Nomor 631/Menkes/ Per/III/2011 Sebagaimana Telah Diubah Dengan Permenkes Nomor 2562/Menkes/Per/XII/2011 tentang Petunjuk Teknis Jaminan Persalinan di RSUD dr. H. Soewondo Kendal}

a. Latar belakang Pelaksanaan Peran Bidan Berdasarkan Permenkes Nomor 631/Menkes/ Per/III/2011 sebagaimana telah diubah dengan Permenkes Nomor 2562/Menkes/Per/XII/2011 tentang Petunjuk Teknis Jaminan Persalinan di RSUD dr. H. Soewondo Kendal

Bidan memiliki peran utama dalam pelaksanaan jaminan persalinan berdasarkan Permenkes Nomor 631/Menkes/Per/III/2011 sebagaimana telah diubah dengan Permenkes Nomor 2562/Menkes/ Per/XII/2011 tentang Petunjuk Teknis Jaminan Persalinan. Karena bidan merupakan garda terdepan dalam pemberi pelayanan jampersal. Peran utama bidan dalam pelaksanaan jaminan persalinan Kewajiban yang diatur dalam perundangundangan, Karena keterkaitan dengan sasaran dalam pelayanan jaminan persalinan

b. Prosedur/mekanisme Pelaksanaan Peran Bidan Berdasarkan Permenkes Nomor 631/Menkes/ Per/III/2011 sebagaimana telah diubah dengan Permenkes Nomor 2562/Menkes/Per/XII/2011 tentang Petunjuk Teknis Jaminan Persalinan di RSUD dr. H. Soewondo Kendal

Prosedur dalam pelayanan jaminan persalinan berjenjang mulai dari pelayanan tingkat dasar (Puskesmas dan Bidan Praktik Mandiri) kemudian jika terdapat kasus kebidanan yang tidak dapat ditangani maka harus dilakukan rujukan kepada tenaga kesehatan yang lebih ahli dan memiliki kewenangan yang lebih dalam pelayanan yaitu pada tingkat lanjutan (Rumah Sakit). Peran bidan dalam prosedur pelayanan jaminan persalinan di RSUD dr. H. Soewondo Kendal yaitu :

1) Peserta datang ke rumah sakit dengan menggunakan surat rujukan dan membawa persyaratan antara lain fotocopy KTP serta buku KIA

2) Bidan memberikan informasi tentang jaminan persalinan dengan syarat yang telah ditentukan

3) Diruang kebidanan bidan menuliskan data yang harus dilengkapi oleh pasien kemudian dimasukkan bersama rekam medik pasien

4) Meminta jaminan persalinan ke verifikator RSUD dr. H. Soewondo Kendal

5) Diberikan batas waktu 2 × 24 jam

c. Bentuk Peran Bidan Dalam Pelaksanaan Permenkes Nomor 631/Menkes/ Per/II/2011 sebagaimana telah diubah dengan Permenkes Nomor Nomor 2562/Menkes/Per/XII/2011 tentang Petunjuk Teknis Jaminan Persalinan di RSUD dr. H. Soewondo Kendal

Bentuk peran bidan dalam pelayanan jaminan persalinan antara lain :

1) Peran Wajib/Imperatif dalam pelayanan jaminan persalinan

Pelayanan persalinan di RSUD dr. H. Soewondo Kendal sesuai dengan kewenangannya, Mencatat semua pelayanan persalinan yang diberikan, Melaporkan semua prosedur persalinan, Edukatif (Penjelasan), Melaksanakan pelayanan persalinan berdasarkan kewenangan bidan yang diatur dalam Permenkes Nomor 1464/Menkes/Per/X/2010 tentang ljin dan Penyelenggaraan Praktik Bidan. 
2) Peran Tidak Wajib/ Fakultatif dalam pelayanan jaminan persalinan

Peran tidak wajib bidan yaitu kegiatan promotif, preventif dan rehabilitatif. Kegiatan promotif yang dilakukan oleh bidan antara lain melaksanakan promotif kebidanan seperti ibu hamil, kegiatan preventif yaitu pencegahan, peran bidan menganjurkan pada ibu nifas untuk selalu mengkonsumsi makan makanan yang bergizi, Kegiatan rehabilitatif merupakan perbaikan, peran yang dilakukan oleh bidan misalnya pasien nifas post sectio cesarea dapat melakukan kunjungan ulang untuk pemeriksaan lebih lanjut yang dilakukan pada rumah sakit di poli kebidanan.

Jika hal itu dianalisis berdasarkan batas kewenangan bidan maka seharusnya bidan di rumah sakit tidak melakukan pelayanan jampersal bagi ibu bersalin (risti) dan komplikasi kebjdanan. Sehingga hanya bisa dilakukan untuk pelayanan KB, nifas dan bayi baru lahir.

d. Pihak-Pihak yang Terkait Dalam Pelaksanaan Peran Bidan Berdasarkan Permenkes Nomor 631/Menkes/ Per/III/2011 sebagaimana telah diubah dengan Permenkes Nomor 2562/ Menkes/Per/XII/2011 tentang Petunjuk Teknis Jaminan Persalinan di RSUD dr. H. Soewondo Kendal

Pihak yang berperan dalam pelaksanaan jaminan persalinan antara lain Direktur Rumah Sakit, Kepala Bidang Pelayanan Keperawatan Rumah Sakit, Kepala Bidang Pelayanan Medik, Kepala Bangsal, Bidan Praktik.

e. Pembinaan dan Pengawasan Dalam Pelaksanaan Peran Bidan Berdasarkan Permenkes Nomor 631/Menkes/ Per/III/2011 sebagaimana telah diubah dengan Permenkes Nomor 2562/Menkes/Per/XII/2011 tentang Petunjuk Teknis Jaminan Persalinan di RSUD dr. H. Soewondo Kendal

Bidan wajib memberikan laporan ke Bagian Keperawatan yang telah ditunjuk sebagai penanggungjawab dari hasil pelaporan bidan praktik. Banyak kendala yang dialami dalam pelaporan ini dilaksanakan karena bidan praktik melaporkan tidak sesuai dengan fakta yang ada. Bidan praktik melaporkan yang baik-baik saja. Tetapi setelah dilakukan sidak bidan praktik banyak yang tidak sesuai dalam pelayanan jaminan persalinan. Karena ada hambatan dalam pelayanan jaminan persalinan yaitu jumlah bidan yang masih terbatas, tempat yang masih terbatas serta pengobatan yang memiliki jumlah terbatas. Hal ini karena dana yang sangat terbatas yang dimiliki oleh Rumah sakit dalam jaminan persalinan. Tidak ada pemasukan dari pasien tetapi pengeluaran yang sangat banyak sehingga tidak sebanding dan penggantian biaya dari Pemerintah Pusat juga sangat terbatas.

4. Faktor-Faktor yang Mempengaruhi Pelaksanaan Permenkes Nomor 631/Menkes/ Per/III/2011 Sebagaimana Telah Diubah Dengan Permenkes Nomor 2562/Menkes/Per/XII/2011 tentang Petunjuk Teknis Jaminan Persalinan di RSUD dr. H. Soewondo Kendal

a. Faktor Teknis

1) Fasilitas Kesehatan/ Sarana Prasarana Kesehatan

2) Upaya pelayanan kuratif dan dibatasi

3) Tenaga Kesehatan

4) Obat-obatan

5) Pendanaan 
b. Faktor Yuridis

Belum dipahami ketentuan tentang pelaksanaan pelayanan jaminan persalinan seharusnya didasarkan pada Permenkes Nomor 1464/Menkes/Per/2010 tentang Ijin dan Penyelenggaraan Praktik Bidan. Dan belum dibuat ketentuan hukum tentang pelayanan jaminan persalinan sebagai peraturan internal rumah sakit, yang meliputi prosedur pelayanan, penugasan tenaga kesehatan, penetapan hak dan kewajiban, serta pengawasan. Disamping berdasarkan Permenkes Jampersal seharusnya didasarkan pula dengan Permenkes Nomor 1464 Tahun 2010 khususnya tentang batasan kewenangan bidan.Jadi selama ini pelayanan jampersal dirumah sakit hanya dilakukan berdasarkan kebiasaan sebagaimana yang dilakukan terhadap pelayanan pasien umum. Semua ini menjadi kendala utama bidan dalam melaksakan pelayanan jampersal, karena tidak menjamin kepastian hukum dan perlindungan hukum bagi bidan.

\section{PENUTUP}

\section{Kesimpulan}

a. Pengaturan Peran Bidan Dalam Pelaksanaan Jaminan Persalinan di RSU dr. H. Soewondo Kendal

Dasar Hukum antara lain Undang-Undang Sistem Jaminan Sosial Nasional Nomor 40 Tahun 2004, Undang-Undang Kesehatan Nomor 36 Tahun 2009, Undang-Undang Rumah Sakit Nomor 44 Tahun 2009, Permenkes Nomor 1464/Menkes/Per/X/2010

Peran bidan didasarkan pada Permenkes Nomor 1464/Menkes/Per/X/2010 yaitu telah melaksanakan tugasnya dengan baik sesuai dengan standar pelayanan yang ditetapkan. Pelayanan yang diberikan antara lain hamil, bersalin, nifas, bayi baru lahir, kesehatan reproduksi. Dalam menjalankan tugas pelayanan persalinan dalam pelaksanan program jampersal sesungguhnya tidak sesuai dengan kewenangan yang diatur dalam ketentuan permenkes ini.

Tujuan Pengaturan Menurunkan angka kematian Ibu dan angka kematian bayi serta pelaksanaan program jaminan persalinan dapat berjalan efektif dan efesien perlu adanya petunjuk teknis.

b. Pelaksanaan Peran Bidan Berdasarkan Permenkes Nomor 631/Menkes/ Per/III/2011 sebagaimana telah diubah Permenkes Nomor 2562/Menkes/Per/XII/2011 tentang Petunjuk Teknis Jaminan Persalinan di RSU dr. H. Soewondo Kendal

Latar belakang pelaksanaan peran bidan dalam pelayanan jaminan persalinan di RSUD dr. H. Soewondo Kendal memberikan pelayanan mulai dari pemeriksaan kehamilan, persalinan, nifas, bayi baru lahir, KB dan kesehatan reproduksi wanita. Pelayanan jaminan persalinan di RSUD dr. H. Soewondo Kendal telah dilaksanakan berdasarkan peraturan yang telah ditetapkan. Pelayanan diberikan dalam rangka melaksanakan program menurunkan Angka Kematian Ibu dan Angka Kematian Bayi.

Prosedur dalam pelayanan jaminan persalinan berjenjang mulai dari pelayanan tingkat dasar (Puskesmas dan Bidan Praktik Mandiri) kemudian jika terdapat kasus kebidanan yang tidak dapat ditangani maka harus dilakukan rujukan kepada tenaga kesehatan yang lebih ahli dan memiliki kewenangan yang lebih dalam pelayanan yaitu pada tingkat lanjutan (Rumah Sakit). 
Bentuk peran bidan dalam pelayanan jaminan persalinan antara lain wajib/ imperaktif dan tidak wajib/ fakultatif . Peran bidan yang wajib yaitu pelayanan persalinan berdasarkan tujuan rumah sakit, mencatat semua pelayanan persalinan yang diberikan, melaporkan semua prosedur persalinan serta edukatif. Peran tidak wajib meliputi promotif, preventif dan rehabilitatif.

Pihak-pihak yang berperan dalam pelaksanaan jaminan persalinan yaitu yang berhubungan langsung dengan pelayanan jaminan persalinan, antara lain Direktur Rumah Sakit, Kepala Bidang Pelayanan Keperawatan Rumah Sakit, Kepala Bidang Pelayanan Medik, Kepala Bangsal, Bidan Praktik.

Bidan wajib memberikan laporan ke Bagian Keperawatan yang telah ditunjuk sebagai penanggungjawab dari hasil pelaporan bidan praktik. Banyak kendala yang dialami dalam pelaporan ini, karena bidan praktik melaporkan tidak sesuai dengan fakta yang ada. Bidan praktik melaporkan yang baik-baik saja.

c. Faktor-Faktor yang Mempengaruhi Pelaksanaan Permenkes Nomor 631/Menkes/ Per/III/2011 sebagaimana telah diubah Permenkes Nomor 2562/Menkes/Per/XII/2011 tentang Petunjuk Teknis Jaminan Persalinan di RSU dr. H. Soewondo Kendal antara lain faktor teknis dan faktor yuridis yaitu belum dipahami ketentuan tentang pelaksanaan pelayanan jaminan persalinan.

\section{Saran}

\section{a. Kementrian Kesehatan}

Perlu ditinjau kembali Permenkes Nomor 631/Menkes/ Per/III/2011 sebagaimana telah diubah dengan Permenkes Nomor 2562/Menkes /Per/XII/2011 tentang Petunjuk Teknis Jaminan Persalinan dan dapat menyusun peraturan tentang jaminan persalinan yang baru untuk meningkatkan pelayanan jaminan persalinan sesuai dengan prosedur teknis berupa rujukan dan pelayanan keluarga berencana.

b. Dinas Kesehatan

Melaksanakan pengawasan dan evaluasi terhadap jalannya program jaminan persalinan yang dilaksanakan oleh fasilitas pelayanan kesehatan, dan melakukan sosialisasi Permenkes Nomor 2562/Menkes/Per/XII/2011 tentang Petunjuk Teknis Jaminan

c. Direktur Rumah Sakit

Diharapkan dapat menyusun peraturan internal rumah sakit tentang kebijakan Direktur dalam jaminan persalinan, pedoman penyelenggaraan program jaminan persalinan di rumah sakit, prosedur klaim pembayaran dan standar prosedur operasional tentang Petunjuk Teknis Jaminan Persalinan

d. Bidan

Dapat memahami prosedur penanganan jaminan persalinan yang ada pada rumah sakit dan melaksanakan pelayanan jaminan persalinan sesuai dengan peraturan yang berlaku. 


\section{DAFTAR PUSTAKA}

Ali Ghufron Mukti, Moertjahjo, 2007, Sistem Jaminan Kesehatan, Jogjakarta, PT. Karya Husada Mukti (K.H.M).

Azrul Anwar, 1996, Pengantar Administrasi Kesehatan Edisi Ketiga Jakarta : Bina Rupa Aksara.

Bambang Purnomo, Hukum Kesehatan, Yogyakarta : Aditya Media.

Beni Ahmad Soebani, 2009, Metode Penelitian Hukum, Bandung : Pustaka Setia.

Binkesmas 1997,Buku Pedoman di desa, Dirjen Binkesmas : Jakarta.

Dep Kes RI, 2005, Standar Pelayanan Rumah Sakit Cetakan IV, Jakarta.

Dep Kes RI, 2005, Rencana Strategis Dep Kes RI.2005-2009, Jakarta.

Dep Kes RI, 2008, Pedoman Pelaksanaan Jaminan Kesehatan Masyarakat, Jakarta.

Endang Wahyati, 2012, Mengenal Hukum Rumah Sakit. Bandung : CV Keni Media.

Eva Fitria, 2008, Menuju Sistem Jaminan Sosial Nasional, GTZ-GVGSHI SUPPORT.

Gunadi, 1991, Pelayanan Kesehatan Rumah Sakit, Rineka Cipta, Jakarta.

Helen varney,et al, 2007, Buku Ajar Asuhan Kebidanan, Jakarta : EGC.

Kusnanto, 2004, Praktek Profesional Perawat, Jakarta, EGC.

Mustika Sofyan, 2006, 50 Tahun IBI. Bidan Menyongsong Masa Depan Cetakan kelima, Jakarta.

Prawiroharjo,YB,PS, 2001, Buku Acuhan Nasional Pelayanan Kesehatan Maternal dan Neonatal ed,1, Jakarta : JNPKKR.POGI.

Pusdiknakes 2000, Konsep Asuhan Kebidanan, Jakarta : Pusdiknakes.

Riyadi Slamet, 1982, Manajemen Pelayanan Kesehatan, Rineka Cipta,: Jakarta.

Satrianegara M.F.S.S, 2009, Buku Ajar Organisasi dan Manajemen pelayanan Kesehatan serta Kebidanan, Jakarta : Salemba Medika.

Selo, Soemardjan Selo dkk, 1996, 50 Tahun IBI : Bidan Menyongsong Masa Depan, Jakarta : Pengurus Pusat IBI.

Soekidjo Notoatmodjo, 1993, Pengantar Kesehatan dan Ilmu Perilaku Kesehatan, Jakarta : Rineka Cipta

Trismatoro, L, 2005, Manajemen Rumah Sakit, Yogyakarta : Gajahmada University Press.

Jurnal dan Sumber dari Internet

Febrina 'Bidan Shop' 12 Pebruari 2010, Standar Praktek Kebidanan. Online Internet 14 Oktober 2011, http//bidan spop, blog spot. Com/2010/01/Bidan Profesional.html.

www.gajimu.com/main/pekerjaan yang layak/jaminan.sosial.

www.jamsosindonesia.com/pras jsn/askes/regulasi.

\section{Peraturan Perundang Undangan}

Undang-Undang Nomor 40 Tahun 2004 tentang Sistem Jaminan Sosial Nasional.

Undang-Undang Nomor 36 Tahun 2009 tentang Kesehatan.

Undang-Undang Nomor 44 Tahun 2009 tentang Rumah Sakit.

Peraturan Pemerintah Nomor 32 Tahun 1996 Tentang Tenaga Kesehatan.

Permenkes Nomor 2562/Menkes/Per/XII/2011 tentang Petunjuk Teknis Jaminan Persalinan.

Permenkes Nomor 1796 Tahun 2011 Tentang Registrasi Tenaga Kesehatan.

Kepmenkes Nomor 369/Menkes/SK/III/2007, Tentang Standar Profesi Bidan.

Surat Edaran Direktur Jendral Pembina Kesehatan Masyarakat No. 429/Binkesmas/DJ/III/89 Pada Tanggal 29 Maret 1989 Tentang Dasar Pelaksanaan Penempatan Bidan Desa Sesuai Dengan Kebijakan Departemen Kesehatan, Jakarta. 